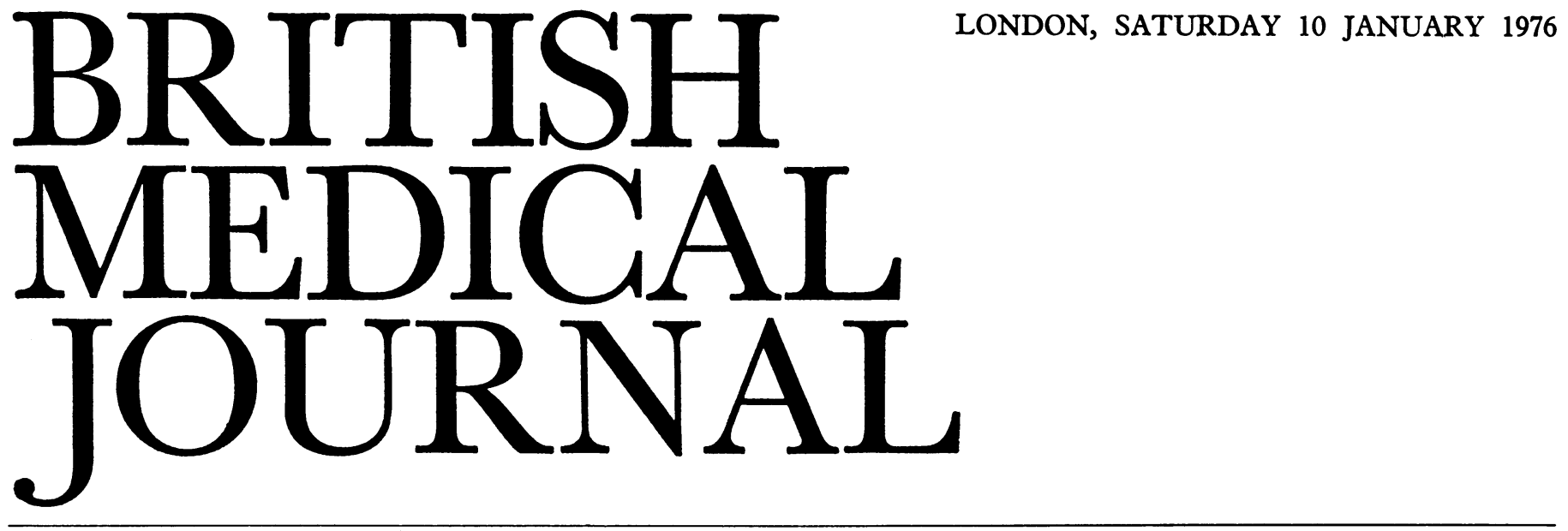

In Britain, as in most advanced countries, most women give birth in maternity hospitals where standards of care and technical skill are so high that very few mothers die, and the death rate among babies has been greatly reduced. The trend towards hospital confinement has been speeded by a series of national reports $^{1-5}$ all deeply concerned with the safety of mothers and babies. So much has been achieved that reversal of the trend is unlikely.

But certain aspects of patient care in maternity hospitals continue to bother some patients and not a few doctors. First is the matter of induction and active management of labour. Where there are convincing medical reasons for interference and a suitable explanation is given to the patient there can be no cause for complaint. Interference for the convenience of patient or doctor is another matter, and the wisdom of this practice has rightly been questioned. ${ }^{6}$ Again, patients and women journalists who write in the national press, speak on the radio, or appear on television not infrequently claim that confinement at home surrounded by their families is a more satisfactory emotional experience and much preferable to hospital confinement, which they say tends to be impersonal with little continuity of care. Provided all has gone well this may be so; but for every one who writes or speaks in this way there must be a hundred less articulate women who are deeply conscious of the debt they and their babies owe to the skill and devotion of midwives and doctors in maternity hospitals. And there clearly are other women and their families who looked forward to the emotional satisfaction of a home confinement but whose dreams were shattered by some complication (usually unforeseen but occasionally foreseeable), which led either to loss of life or severely prejudiced the future wellbeing of mother or child. In some of these cases had the mother been in a maternity hospital the outcome might have been different. Seldom are their tragic experiences related in public.

Another criticism, increasingly heard, is that the facilities for home confinement are being withdrawn so rapidly that women who want to have their babies in their own homes find it difficult to make suitable arrangements. Behind this criticism is the persistent belief that selected groups of "low risk" cases may safely be delivered at home. In practice this has proved difficult to achieve. The National Perinatal Mortality Survey $^{3}$ gave evidence of poor selection for home delivery and found that there was a considerable risk to the baby when the mother had to be transferred to hospital late in pregnancy or during labour. Similar evidence of poor selection for home confinement and failure to arrange early enough transfer to hospital is reported by Cox and his colleagues in a paper at page 84 -this in spite of the fact that their study was carried out in an area with excellent family doctors who were apparently aware of the research project and its aims. A disturbing feature for those who believe that home confinement will avoid the artificial onset of labour is that 14 of the 155 women booked for domiciliary confinement had their labours artificially induced; and half the babies with problems at birth were in the obstetric "low risk" group. Among the babies delivered were several examples of failure to diagnose or interpret clinically significant signs during the neonatal period. These babies were placed at some risk.

Though $90 \%$ of British women now have their babies in hospital, there is still a vociferous lobby in favour of a substantial swing back to domiciliary confinement. It is commonly argued that babies born in hospital are more liable to suffer serious infection, that the Dutch have low fetal death rates in spite of a high incidence of domiciliary confinement, and that an efficient obstetric flying squad can adequately take care of emergencies arising in the home. None of these arguments is convincing. In the National Perinatal Mortality Survey ${ }^{3}$ deaths from neonatal pneumonia were commoner among babies delivered at home, and a large-scale community study of maternity in Newcastle upon Tyne ${ }^{7}$ showed that perinatal death from infection was less common in the city's two large hospitals than among babies delivered at home. The better performance of Dutch women is closely related to their superior height and good health: Baird ${ }^{8}$ has reported that they are, on average, 3 in $(7.5 \mathrm{~cm})$ taller than Aberdeen women. They are between two and three times less likely than British women to lose their babies on account of severe malformations of the central nervous system $^{9}$; and De Hass-Porthuma ${ }^{10}$ has shown that those parts of Holland with the highest incidence of hospital confinement have the lowest perinatal mortality rates. Finally, though an efficiently organised flying squad can be of great help, it does take time to move help from hospital to a patient's home-and time is never on the patient's side.

The pressing need is for a review of all aspects of patient care in maternity hospitals so as to make the mother's stay more congenial without losing any of the discipline which is so essential to the safety of mother and baby. The price of safe and happy childbirth is eternal vigilance, and this is 
precisely what a well-organised maternity hospital should offer.

${ }^{1}$ Ministry of Health, Department of Health and Social Security, Reports on Confidential Enquiries into Maternal Deaths in England and Wales 1952-1969. London, HMSO, 1957-1972.

2 Ministry of Health, Report of the Maternity Services Committee. London, HMSO, 1959.

${ }^{3}$ Butler, N R, and Bonham, D G, Perinatal Mortality, First Report of British Perinatal Mortality Survey. London, Livingstone, 1963.

4 Butler, N R, and Alberman, E D, Perinatal Problems, Second Report of British Perinatal Mortality Survey. London, Livingstone, 1969.

${ }^{5}$ Department of Health and Social Security, Standing Maternity and Midwifery Advisory Committee, Domiciliary Midwifery and Maternity Bed Needs. London, HMSO, 1970.

6 Lancet, 1974, 2, 1183.

7 Russell, J K, Lancet, 1966, 1, 1315.

${ }^{8}$ Baird, D, Obstetrical and Gynecological Survey, 1965, 20, 410.

9 Baird, D, fournal of Biosocial Science, 1971, 3 suppl, 93.

$10 \mathrm{De}$ Hass-Porthuma, J H, Proceedings of the Organisation for Health Research, Series $A$, no 11, 220. The Hague, TNO, 1963.

\section{Women in medicine}

The new legislation ${ }^{1}$ against sex discrimination in employment (which came into force last week) gives added topicality to the discussion of the problems of women in medicine published at $\mathrm{p} 78$ - the second session of the BMF conference on medical manpower held at Canterbury in November. The proportion of women entering the medical profession has been rising in Western countries and has now reached nearly $40 \%$ in Britain and will reach $50 \%$ by the 1980 s if current trends continue. ${ }^{2}$ We are still, however, a long way from the female domination of medicine found in the USSR and some other communist states.

In the past far too many women doctors have dropped out of medicine within a few years of qualification in order to look after their husbands and children, and relatively few ever returned to full-time work. If this pattern of behaviour were to persist, its cost to society would rise with the rising numbers of women doctors and soon become unacceptably high. Recognition of this fact has led to some action by the Department of Health-its retainer and training schemes for women doctors-but the underlying problems have yet to be tackled with any real conviction.

Women do not seek, nor should they be given, any special treatment or favour on the grounds of sex when they compete with men at undergraduate or postgraduate levels on equal terms. While fewer than half the applicants for medical school places are women they may be expected to be (on average) academically better qualified than men, so it should not be surprising that their final examination results are better. $^{3}$ Any woman doctor who decides to make a career in a prestigious specialty such as neurology or cardiothoracic surgery will find that she is competing with men who give $100 \%$ of their effort to their work: she cannot expect to succeed if she tries to combine her specialist training with bringing up a family herself. It would be quite wrong for any modification to be made to the existing system to encourage part-time training in such demanding branches of medicine, for standards would inevitably fall.

But some men and more women will never want to pursue a career which demands near total commitment for many years. Some specialties are less demanding than others in terms of hours on call, the academic standard required in postgraduate examinations, and the competition for vacant posts. They also tend to be less popular-these are the shortage specialties, in which a disproportionately large number of hospital junior staff come from overseas and to which recruitment is difficult. Why expect women to fill these less attractive posts, it may be asked. The answer is that the selection factor is not sex: it is the wish for a less-thanmaximum commitment.

There are many jobs in medicine that can be done part-time and yet provide worthwhile, satisfying careers. Married women need not be condemned-in Dr Tom Arie's phraseto a soul-destroying routine of contraceptive clinics. Psychiatry, anaesthetics, and many other hospital disciplines; community health; and general practice can all provide work for part-timers if the good will and motivation are there. There are some financial anomalies which make for difficulties: for example, a general practitioner who wants to take on a part-time partner may find that the only way it can be done is to employ her as an assistant-at a considerable financial loss to the practice and the doctor concerned. In general, medical assistants are worse paid than doctors in the hospital practitioner grade-a consequence of the multiheaded negotiating system within the NHS, but an anomaly that causes serious resentment within the hospital service. Just as there is a clear case for the manpower policies for the whole NHS to come under the umbrella of a single planning unit, so too there should be closer comparability of all NHS salaries-and this should be possible since they are agreed within a single framework.

While openings exist in these specialties for part-time work-including part-time specialist training-there are still far too few career appointments which offer less than full-time contracts. In part this is simply inertia: if the establishment of a hospital has always been filled with wholetime and maximum part-time posts, it is simpler and easier to continue with the status quo. Furthermore, there are practical arguments against part-time appointments, ${ }^{4}$ which inevitably will be advanced if suggestions for change are made.

But, as our conference showed, times are changing. Alterations in the taxation laws and improved hospital salary scales have made it more rewarding for young women doctors to continue working after marriage, and many more seem to be doing so-perhaps encouraged by the bleak economic climate. Those who dropped out a few years ago to have families are anxious to return to work-and, as Dr Peter Clark and others have shown, will do so eagerly given only a little active encouragement and practical help. Yet the arrangements are still amateurish and betray a Departmental attitude of laisser faire. Surely if nearly half our young doctors are women, most of whom will marry and have children, more formal provision should be made for part-time work in planing the staffing structure of the NHS. One of the Service's unsolved problems is the disparity between the numbers of training posts needed in the hospital service and the numbers needed to staff the junior grades. Part of the solution could come from more and better use of the pool of medical women willing to work part time. The recent legislation about equal opportunity gives an impression of politically motivated window-dressing rather than real reform. What is wanted in the NHS is practical provision for the needs of women who wish to combine medicine with marriage without damage to the standards of either.

\footnotetext{
1 Sex Discrimination Act, 1975.

2 Bewley, B, Lancet, 1975, 2, 270

3 Stanley, G R, and Last, J M, British fournal of Medical Education, 1968, 2, 204.

${ }^{4}$ Dollery, C T, British Medical fournal, 1975, 4, 750.
} 